\title{
Power Analysis of Sensor Node Using Simulation Tool
}

\author{
R. Sittalatchoumy ${ }^{1}$, R. Kanthavel ${ }^{2}$, R. Seetharaman ${ }^{1}$ \\ ${ }^{1}$ Department of Electronics and Communication Engineering, Anna University, Chennai, India \\ ${ }^{2}$ Department of Electronics and Communication Engineering, Velammal Engineering College, Chennai, India \\ Email: sittalatchoumy@annauniv.edu,kanthavel2005@gmail.com,rseetharamanece@annauniv.edu
}

How to cite this paper: Sittalatchoumy, R., Kanthavel, R. and Seetharaman, R. (2016) Power Analysis of Sensor Node Using Simulation Tool. Circuits and Systems, 7, 42364247.

http://dx.doi.org/10.4236/cs.2016.713348

Received: May 9, 2016

Accepted: May 21, 2016

Published: November 29, 2016

Copyright $\odot 2016$ by authors and Scientific Research Publishing Inc. This work is licensed under the Creative Commons Attribution International License (CC BY 4.0).

http://creativecommons.org/licenses/by/4.0/

\begin{abstract}
Power consumption of sensor node is analyzed in this paper. In order to analyze the energy consumption, the node model is simulated using Proteus Software tool. The proposed sensor node's power characteristics are measured by using different combinations of microprocessors and sensors. Using this, the energy consumption of the node is calculated. This is a cost-effective method and provides appropriate power model for specific applications.
\end{abstract}

\section{Keywords}

Wireless Sensor Networks, Microcontroller, Lifetime, Differential Encoding

\section{Introduction}

Wireless sensor networks technology has various applications such as surveillance and information gathering in the uncontrollable area of human. In order to further increase the applicability in real world applications, minimizing power consumption is one of the most critical issues. Therefore, accurate power model is required for the evaluation of wireless sensor networks [1] [2]. In a typical temperature measurement, successive samples do not vary much over time. Samples are highly correlated over time (Temporal Correlation). Hence, the difference between adjacent samples has a variance that is smaller than the variance of the signal itself. Instead of transmitting the samples per second by transmitting the difference between samples, the number of bits is reduced. Thus, the transmitting power is reduced which in turn reduces the overall power consumption of the sensor node. Hence, differential encoding offers a way to increase the lifetime [3] [4]. Different types of microcontroller are available which have different internal architecture, power consumption, speed and instruction set [5]. Also, sensors 
vary in their power consumption.

Hence, by trying different combinations of microcontroller and sensor and measuring their power usage and lifetime [6], we can find the optimum node design.

\section{Block Diagram}

To capture the power consumption, a digital oscilloscope was set up to measure the voltage $\mathrm{v}(\mathrm{t})$ over a series resistor $\mathrm{R}$. A small resistance value was chosen in order to minimize additional voltage drop. The setting is shown below in Figure 1. During measurement the oscilloscope has been set up to use as much as possible of the available resolution.

Different types of microcontroller are available which have different internal architecture, power consumption, speed and instruction set [7] [8]. Also, sensors vary in their power consumption. Hence, by trying different combinations of microcontroller and sensor and measuring their power usage and lifetime, we can find the optimum node design. The output of the microcontroller is in parallel form. Since, temperatures are inherently, computed and processed in $\mathrm{BCD}$ form, it makes the processing easier. In order to convert the parallel data into serial, a multiplexer is used. The select lines are generated from a counter, the frequency of which decides the output frequency of the multiplexer.

\subsection{Low Pass Filtering}

The output of the multiplexer is digital. For the purpose of modulation, it is also multiplied with high frequency sine wave. To avoid abrupt transitions in the modulated wave, the digital output of multiplexer must be smoothened [9]. There will be sharp discontinuities which result in the signal having an unreasonably wide bandwidth. Band limiting is generally introduced before transmission, in which case these discontinuities would be "rounded off". The band limiting may be applied to the digital message, or the modulated signal itself. In order to execute this function, a LPF is used.

\subsection{Analog to Digital Conversion}

An analog-to-digital converter is used to analog signal into digital. The conversion

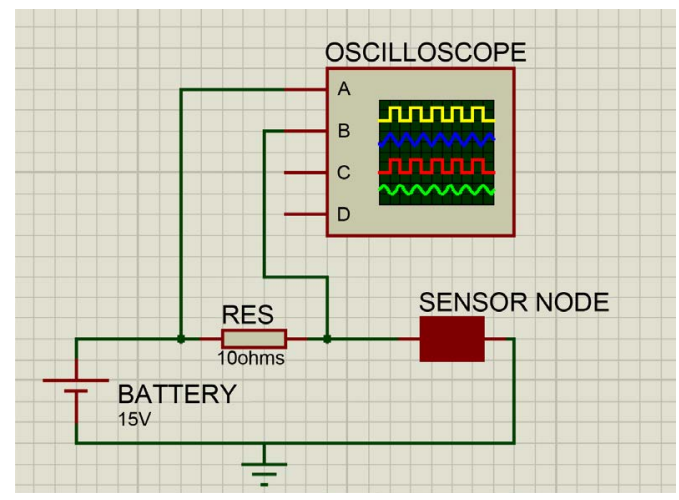

Figure 1. Block diagram. 
involves quantization of the input, so it necessarily introduces a small amount of error [10]. Instead of doing a single conversion, an ADC often performs the conversions ("samples" the input) at regular intervals. The result is a sequence of digital values that have converted a continuous-time and continuous-amplitude analog signal to a discrete-time and discrete-amplitude digital signal.

When an analog sensor (e.g. LM 35) is used and microcontroller doesn't have an inbuilt ADC, an external ADC is used.

\subsection{Binary Amplitude Shift Keying}

Binary Amplitude shift Keying is used in this model (ASK). The advantage of using ASK scheme is that it has a simple modulation and demodulation technique. Since, the output of the sensor node is in burst rather than continuous form, ASK offers a simple transmission scheme within tolerable average probability of symbol error.

\section{Formulae Used}

Total energy consumed $=\Sigma\left(\right.$ power for active mode ${ }^{\star}$ active time $)+\Sigma($ power for sleep mode ${ }^{*}$ sleep time).

Average power consumed $=$ Total energy/Total time.

Energy supplied from the battery $=$ voltage ${ }^{\star}$ current ${ }^{\star}$ time.

Lifetime of the sensor node $=$ energy from battery/average power consumed.

By placing the Microcontroller and sensor, the temperature measurement was carried out. The readings were taken using the in-build Oscilloscope. To estimate the lifetime of sensor node, the power characteristics of sensor node were measured by calculating voltage drop across the resistor and calculating the current. This operation was repeated for various Microcontrollers and Sensors at different temperatures. The parameters measured are substituted in the formulae and thus the lifetime of the sensor node can be calculated.

In Figure 2, ATMEL 89C51 Microcontroller is connected with DS18B20 digital temperature sensors and the temperature reading are given as the input for the Microprocessor. The digitized output is combined with carrier frequency generated by the oscillator and the Amplitude shift keying response is viewed using cathode ray oscilloscope. From the response, the voltage and Current are noted. Using this, the Power consumed by the node is calculated. From the reading the lifetime of the sensor node is calculated.

The Microcontrollers and sensors are varied and the lifetime of the sensor node was calculated and readings are tabulated in Tables 1-3 respectively.

\section{Simulated Output}

Figures 3-7 shows the waveforms associated with various Microcontroller and temperature sensors.

\subsection{Calculations}

Power calculated from the graph, $\mathrm{W}=0.6348 \mathrm{~mW}$ 


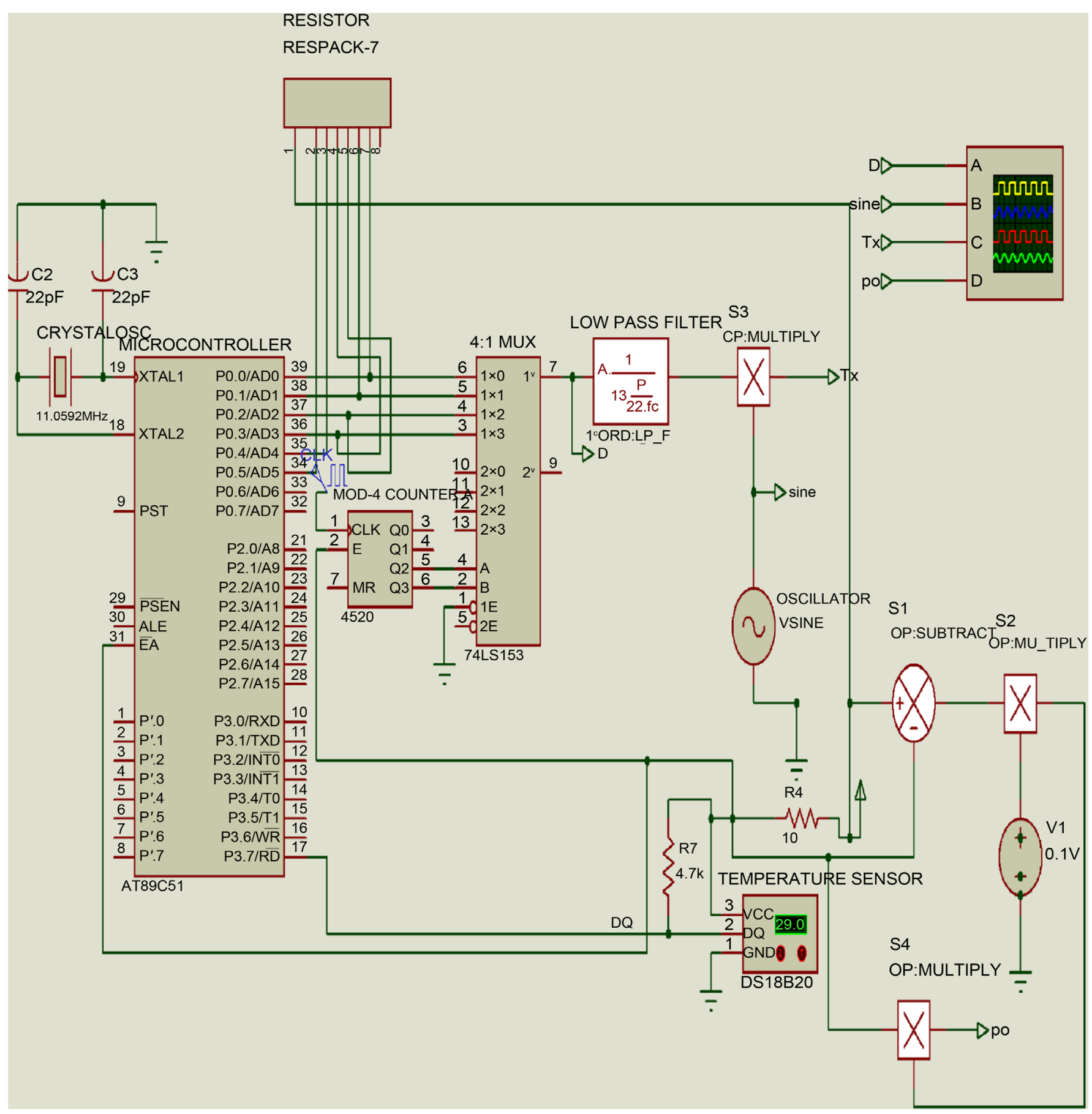

Figure 2. ATMEL 89C51 with DS18B20 digital temperature sensor.

Energy supplied by the battery, $\mathrm{E}=5 \mathrm{~V} * 500 \mathrm{mAh}$

$$
=2.5 \mathrm{Wh}
$$

Lifetime of Sensor Node (in Hrs) $=\mathrm{E} / \mathrm{W}$

$$
=3938.16 \mathrm{hrs}
$$

Lifetime of Sensor Node (in Days) $=3709 / 24$

$$
=164.09 \text { days }
$$


Table 1. Lifetime and power consumption comparison between different microcontrollers and sensors at $25^{\circ} \mathrm{C}$.

\begin{tabular}{cccc}
\hline Microcontroller & Sensor & Power consumption $(\mathrm{mW})$ & Lifetime (days) \\
\hline ATMEGA16 & DS18B20 & 0.5975 & 174.33 \\
ATMEGA16 & LM35 & 0.636 & 163.76 \\
PIC16F887A & DS18B20 & 0.6101 & 170.72 \\
PIC16F887A & LM35 & 0.6348 & 164.09 \\
AT89C51 & DS18B20 & 0.6407 & 162.58 \\
AT89C51 & LM35 & 0.6904 & 150.88 \\
\hline
\end{tabular}

Table 2. Lifetime and power consumption comparison between different microcontrollers and sensors at $30^{\circ} \mathrm{C}$.

\begin{tabular}{cccc}
\hline Microcontroller & Sensor & Power consumption $(\mathrm{mW})$ & Lifetime (days) \\
\hline ATMEGA16 & DS18B20 & 0.6225 & 167.34 \\
ATMEGA16 & LM35 & 0.657 & 158.55 \\
PIC16F887A & DS18B20 & 0.6321 & 164.79 \\
PIC16F887A & LM35 & 0.6578 & 158.36 \\
AT89C51 & DS18B20 & 0.6617 & 157.42 \\
AT89C51 & LM35 & 0.7154 & 145.61 \\
\hline
\end{tabular}

Table 3. Lifetime and power consumption comparison between different microcontrollers and sensors at $35^{\circ} \mathrm{C}$.

\begin{tabular}{cccc}
\hline Microcontroller & Sensor & Power Consumption $(\mathrm{mW})$ & Lifetime (days) \\
\hline ATMEGA16 & DS18B20 & 0.6435 & 161.88 \\
ATMEGA16 & LM35 & 0.679 & 163.76 \\
PIC16F887A & DS18B20 & 0.6551 & 170.72 \\
PIC16F887A & LM35 & 0.6818 & 164.09 \\
AT89C51 & DS18B20 & 0.6867 & 162.58 \\
AT89C51 & LM35 & 0.7374 & 150.88 \\
\hline
\end{tabular}

\subsection{Calculations}

Power calculated from the graph, $\mathrm{W}=0.6407 \mathrm{~mW}$

Energy supplied by the battery, $\mathrm{E}=5 \mathrm{~V} * 500 \mathrm{mAh}$

$$
=2.5 \mathrm{Wh}
$$

Lifetime of Sensor Node (in Hrs) = E/W

$$
=3901.92 \mathrm{hrs}
$$

Lifetime of Sensor Node (in Days) $=3901.92 / 24$

$$
=162.58 \text { days }
$$

\subsection{Calculations}

Power calculated from the graph, $\mathrm{W}=0.6904 \mathrm{~mW}$ 


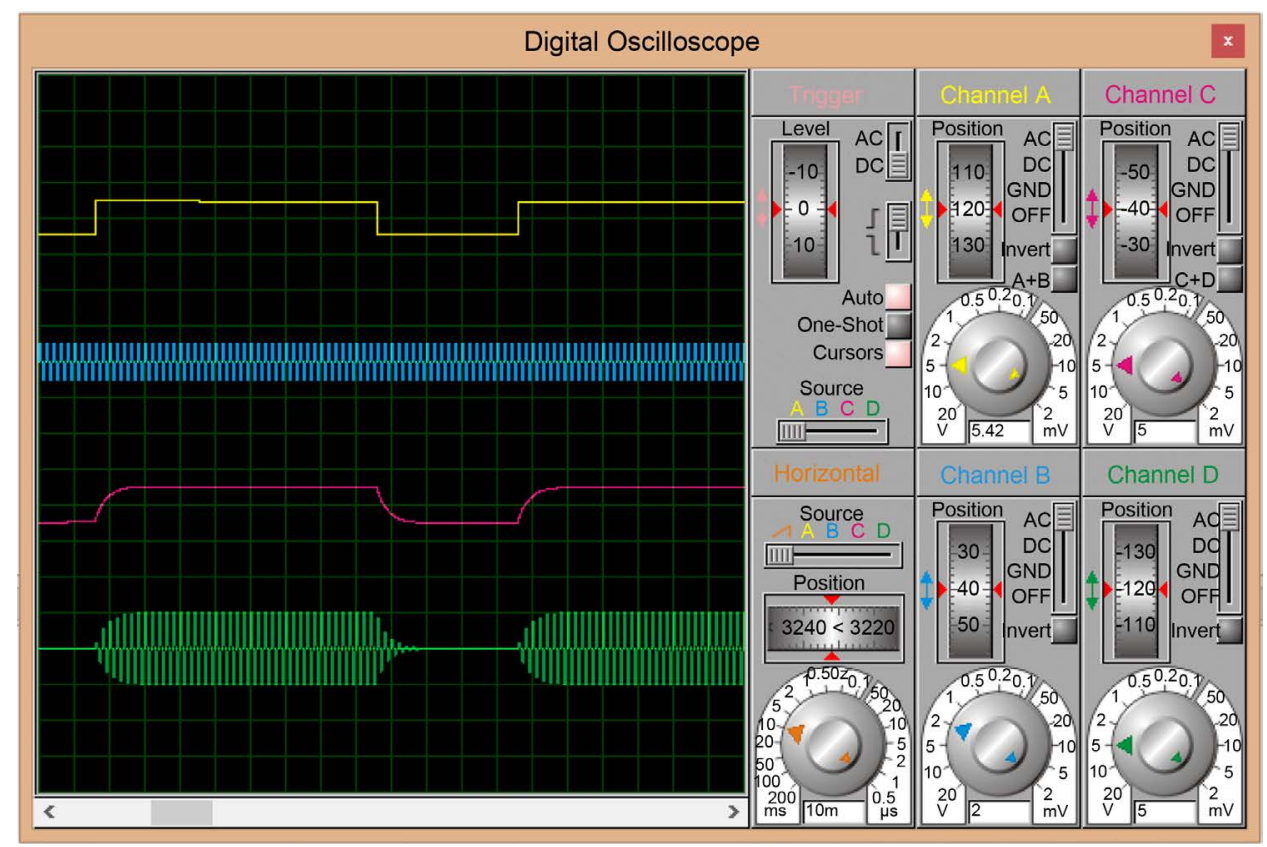

Figure 3. Oscilloscope output for PIC 16F877A with LM35.

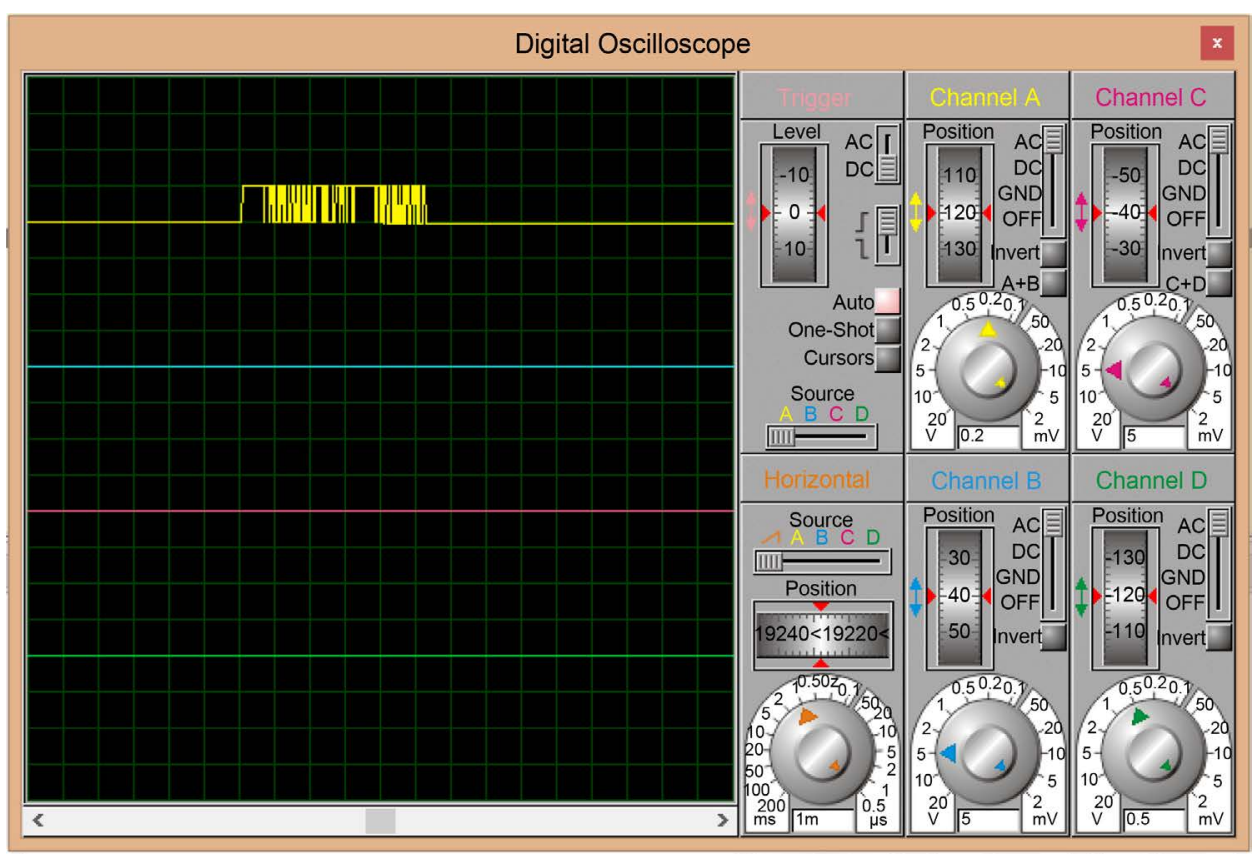

Figure 4. Oscilloscope output for PIC 16F877A with LM35.

Energy supplied by the battery, $\mathrm{E}=5 \mathrm{~V} * 500 \mathrm{mAh}$

Lifetime of Sensor Node (in Hrs) $=\mathrm{E} / \mathrm{W}$

$$
=3621.12 \mathrm{hrs}
$$

Lifetime of Sensor Node (in Days) $=3621.12 / 24$

$$
=150.88 \text { days }
$$




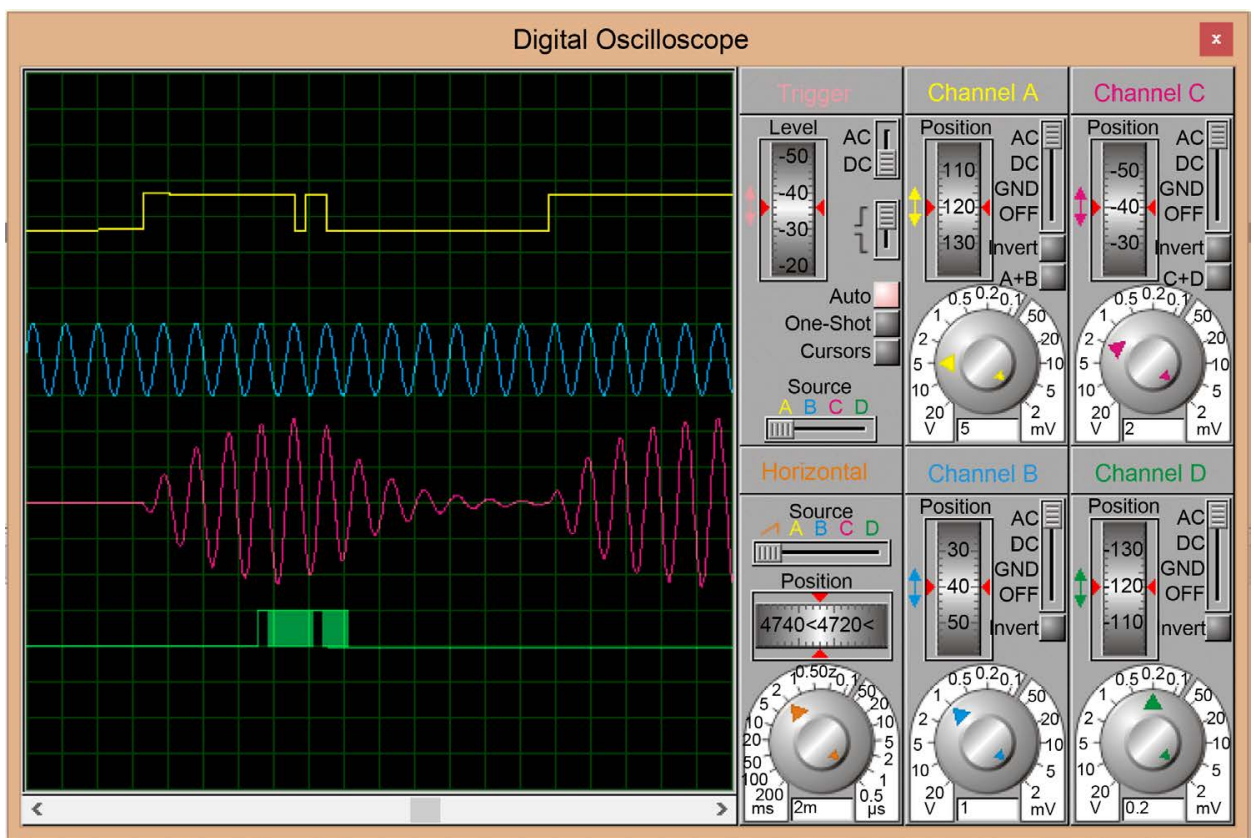

Figure 5. Oscilloscope output for AT89C51 with DS18B20.

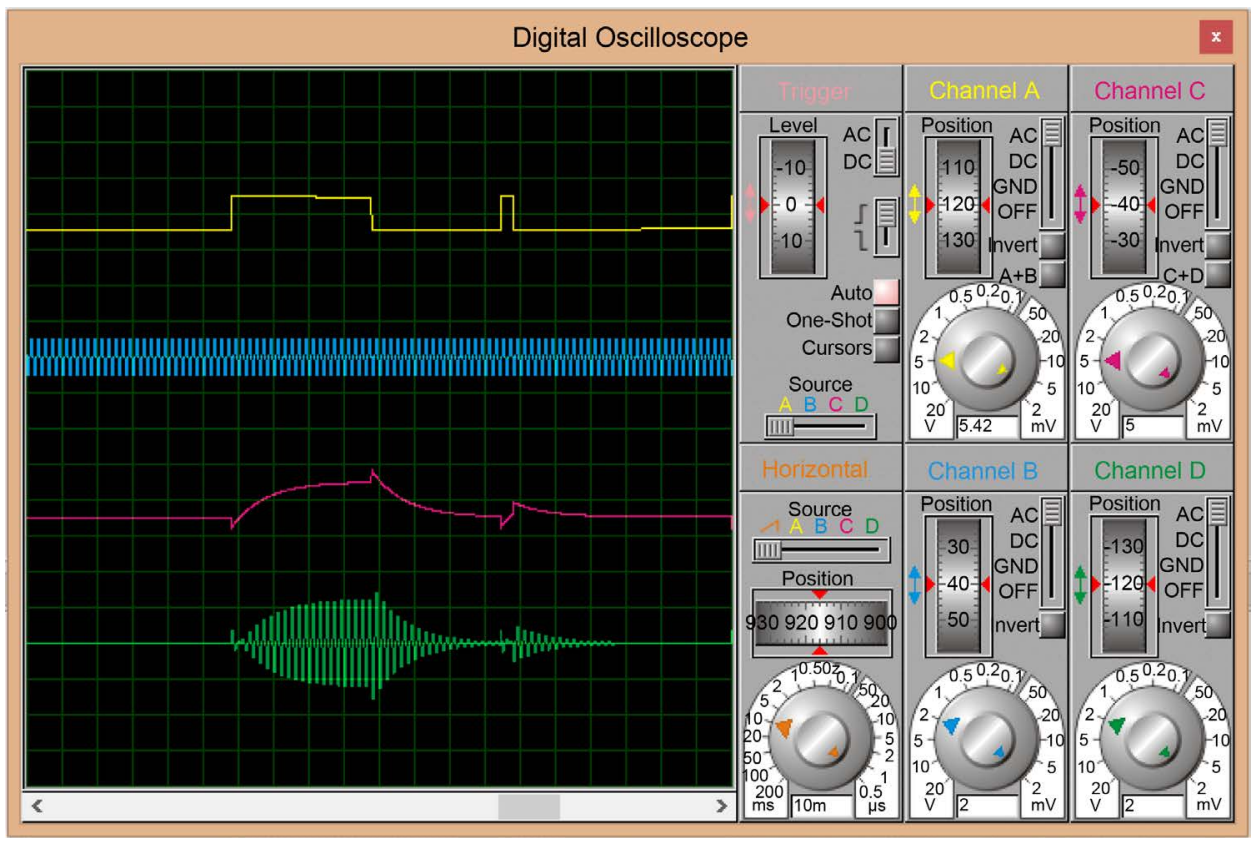

Figure 6. Oscilloscope output for AT89C51 with LM35.

\subsection{Calculations}

Power calculated from the graph, $\mathrm{W}=0.5975 \mathrm{~mW}$

Energy supplied by the battery, $\mathrm{E}=5 \mathrm{~V} * 500 \mathrm{mAh}$

$$
=2.5 \mathrm{Wh}
$$

Lifetime of Sensor Node (in Hrs) $=\mathrm{E} / \mathrm{W}$

$$
=4183.92 \mathrm{hrs}
$$




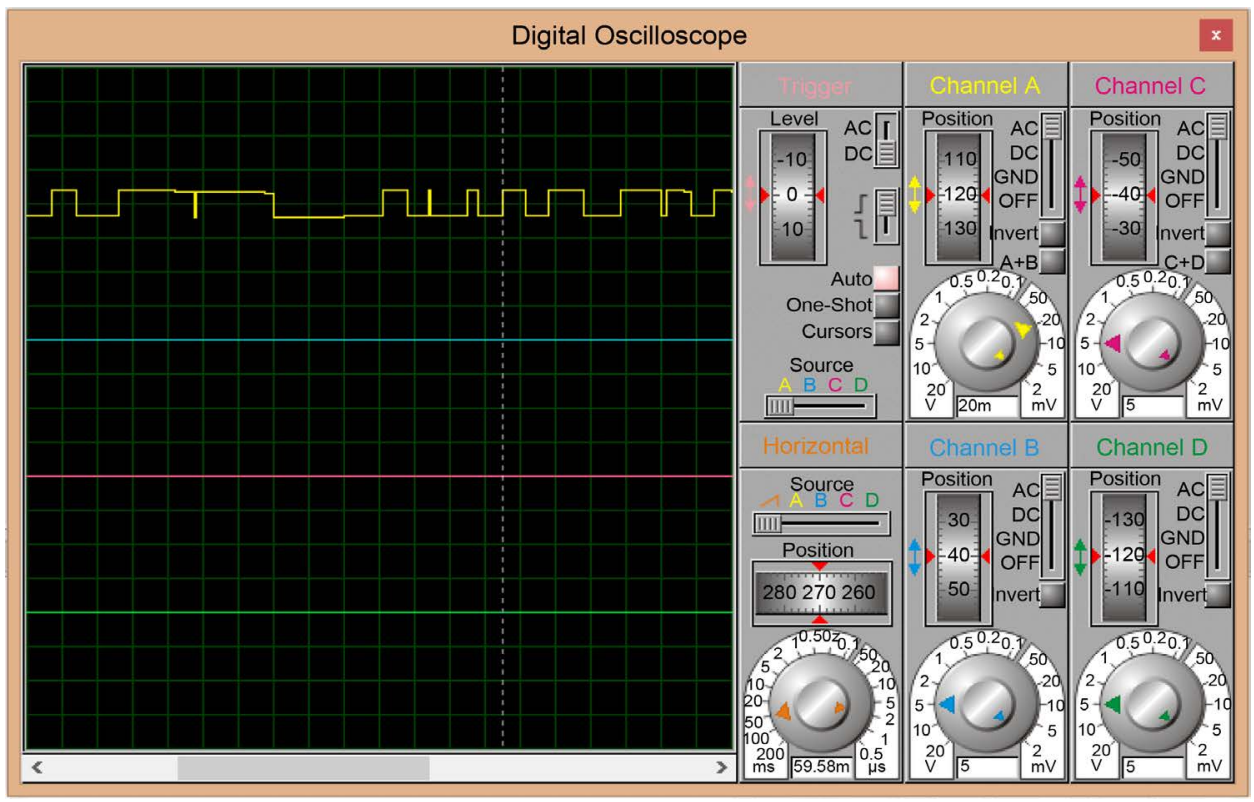

Figure 7. Oscilloscope output for AT89C51 with LM35.

$$
\begin{aligned}
\text { Lifetime of Sensor Node (in Days) } & =4183.92 / 24 \\
& =174.33 \text { days }
\end{aligned}
$$

\subsection{Calculations}

Power calculated from the graph, $\mathrm{W}=0.6101 \mathrm{~mW}$

Energy supplied by the battery, $\mathrm{E}=5 \mathrm{~V} \star 500 \mathrm{mAh}$

$$
=2.5 \mathrm{Wh}
$$

Lifetime of Sensor Node (in Hrs) = E/W

$$
=4097.28 \mathrm{hrs}
$$

Lifetime of Sensor Node (in Days) $=4097.28 / 24$

$$
=170.72 \text { days }
$$

\subsection{Calculations}

Power calculated from the graph, $\mathrm{W}=0.636 \mathrm{~mW}$

Energy supplied by the battery, $\mathrm{E}=5 \mathrm{~V} * 500 \mathrm{mAh}$

$$
=2.5 \mathrm{Wh}
$$

Lifetime of Sensor Node (in Hrs) $=$ E/W

$$
=3930.24 \mathrm{hrs}
$$

Lifetime of Sensor Node (in Days) $=3930.24 / 24$

$$
=163.76 \text { days }
$$

The readings were tabulated from Tables 1-3 and using these readings, the Bar Chart representation was plotted and it is shown in Figure 8-15.

\section{Conclusions}

The results of this study reveal that, ATMEGA16 microcontroller used in combination 


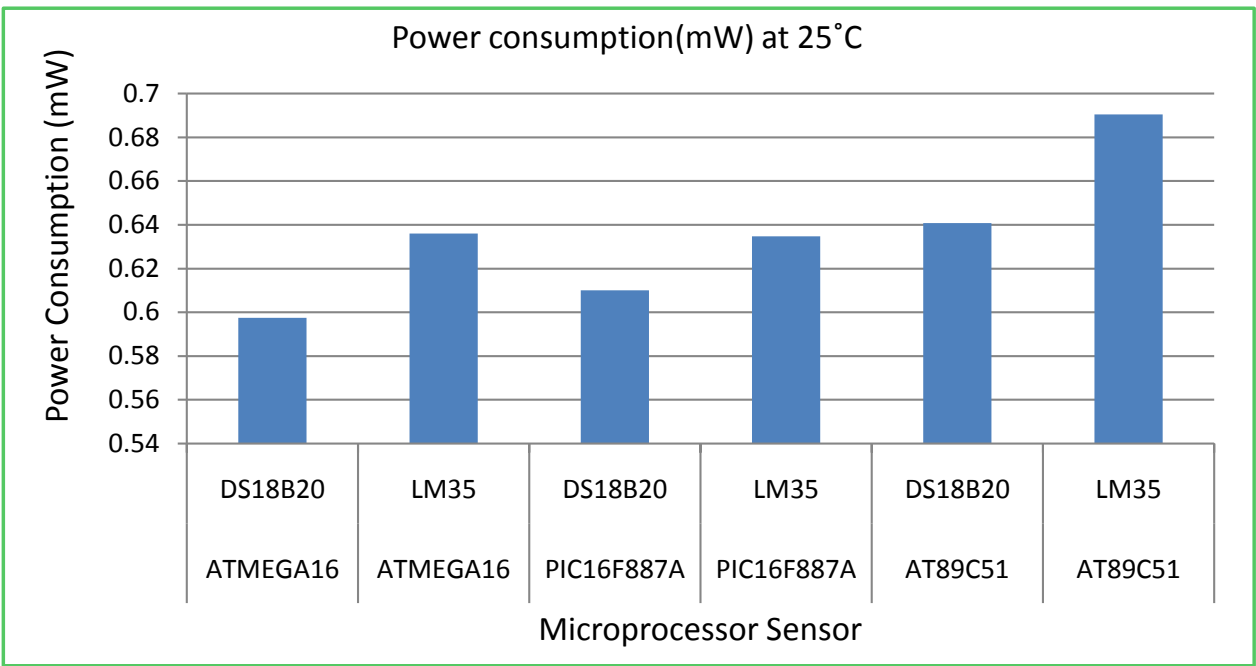

Figure 8. Power consumption at $25^{\circ} \mathrm{C}$.

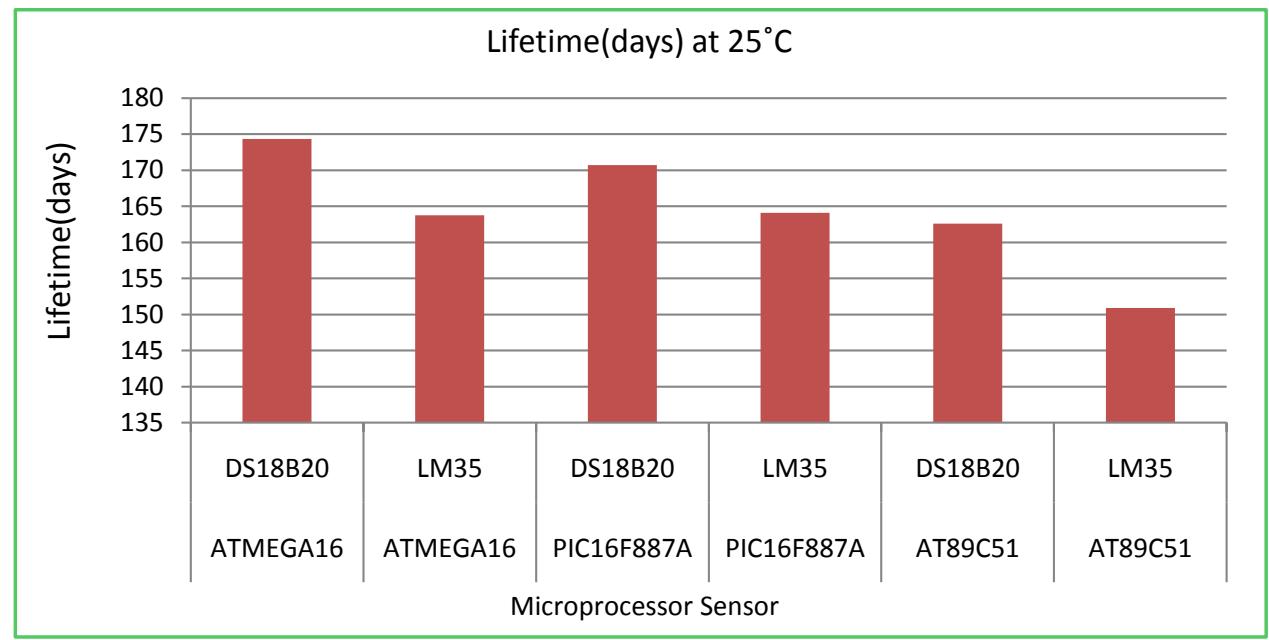

Figure 9. Lifetime at $25^{\circ} \mathrm{C}$.

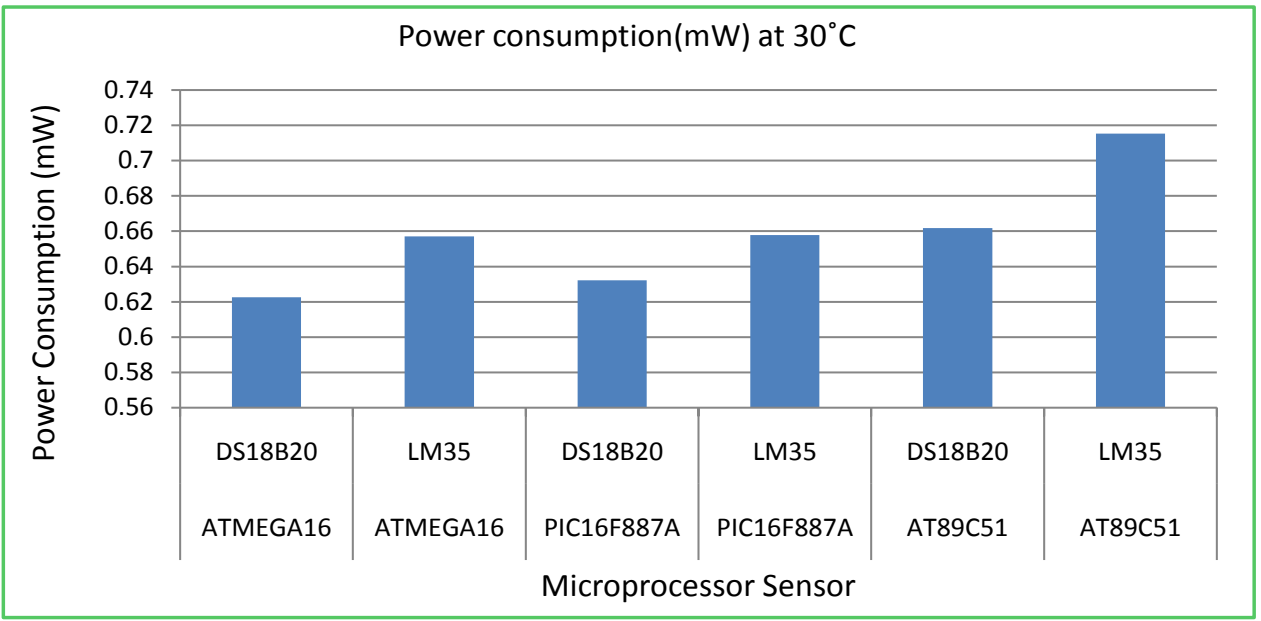

Figure 10. Power consumption at $30^{\circ} \mathrm{C}$. 


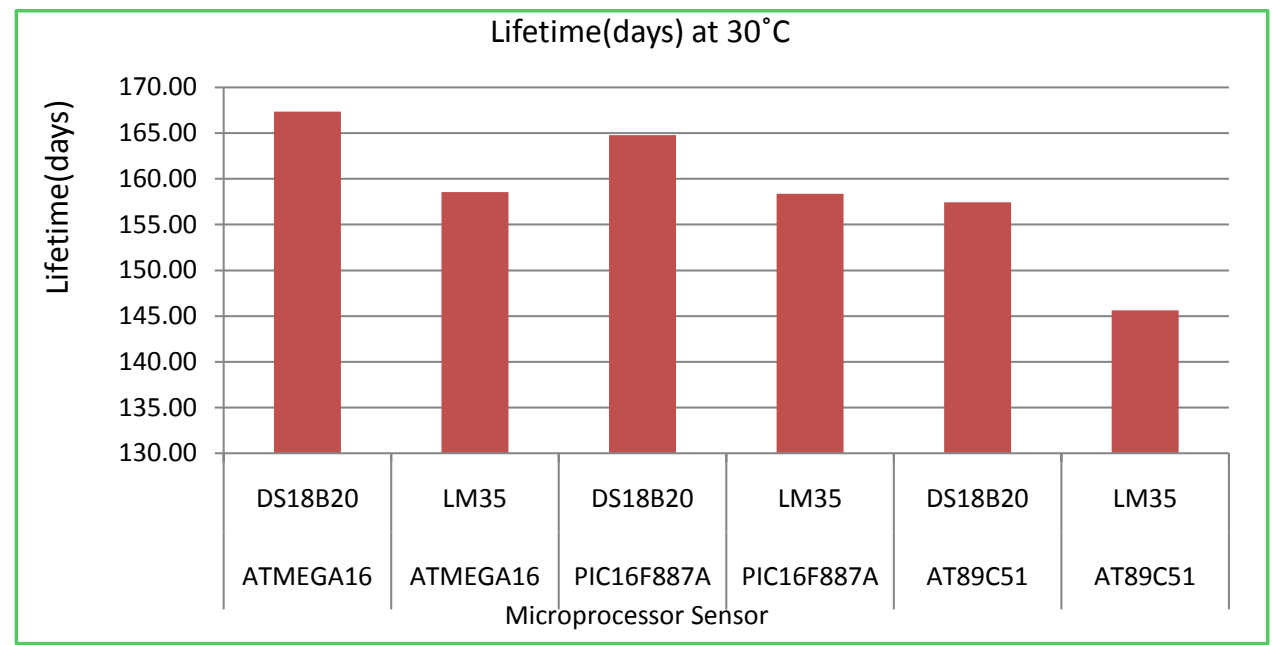

Figure 11. Lifetime at $30^{\circ} \mathrm{C}$.

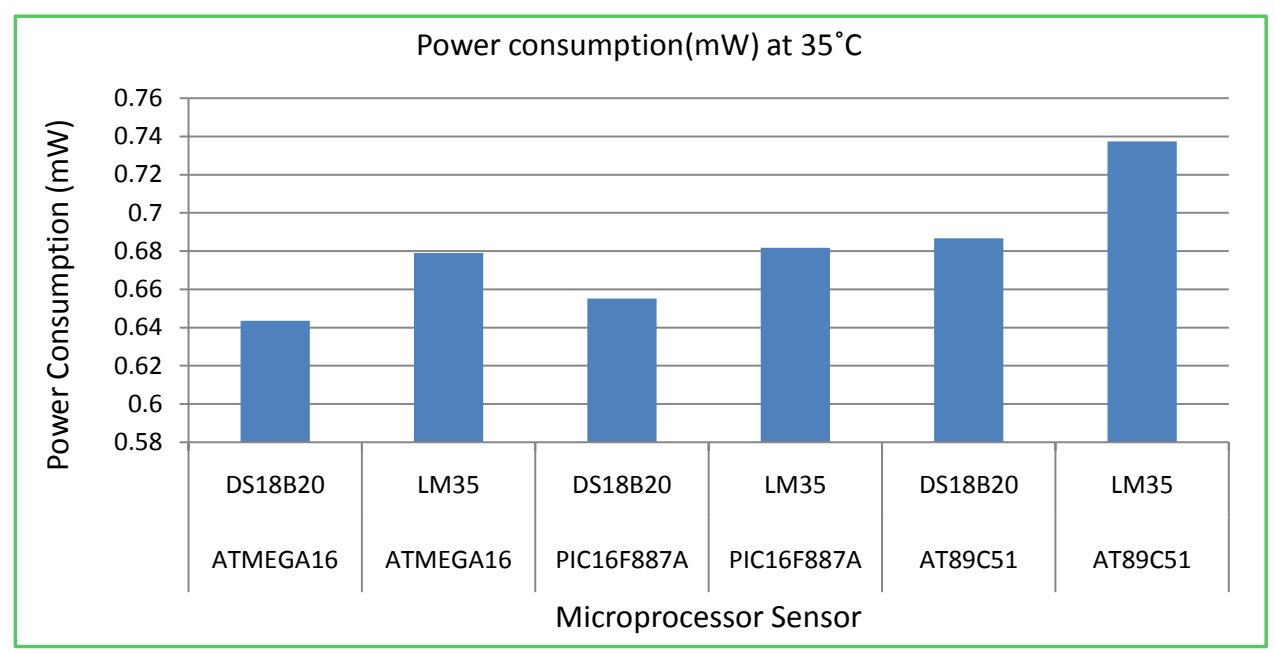

Figure 12 . Power consumption at $35^{\circ} \mathrm{C}$.

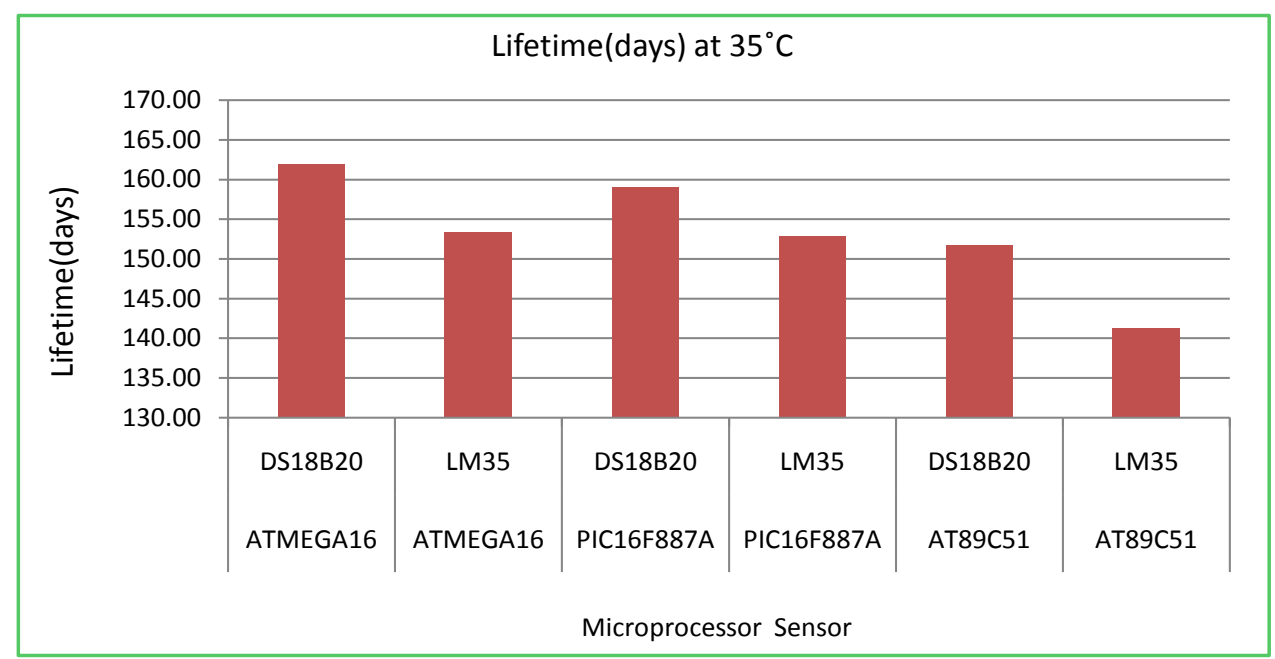

Figure 13. Lifetime at $35^{\circ} \mathrm{C}$. 


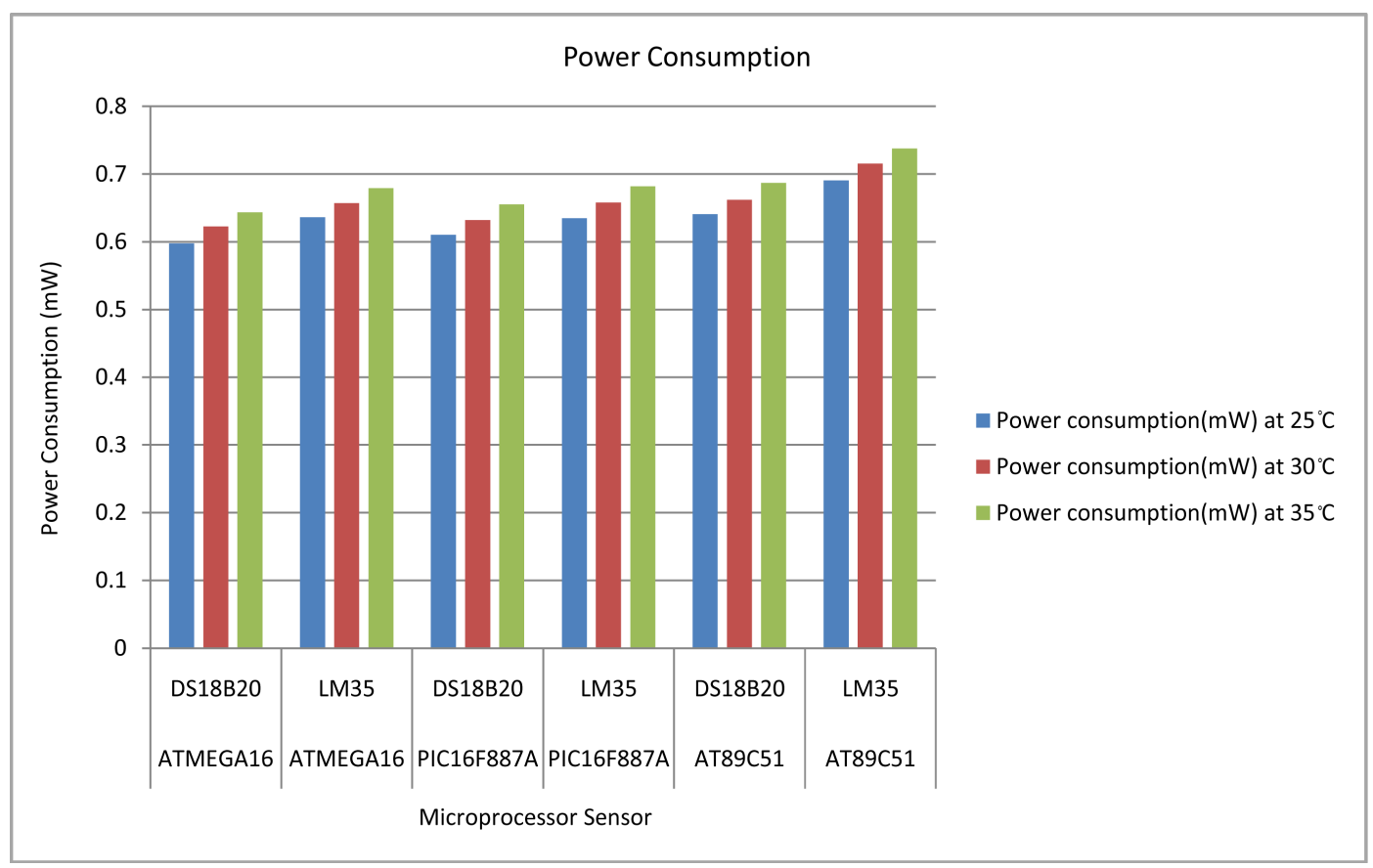

Figure 14. Power consumption comparison of various sensors and microcontrollers.

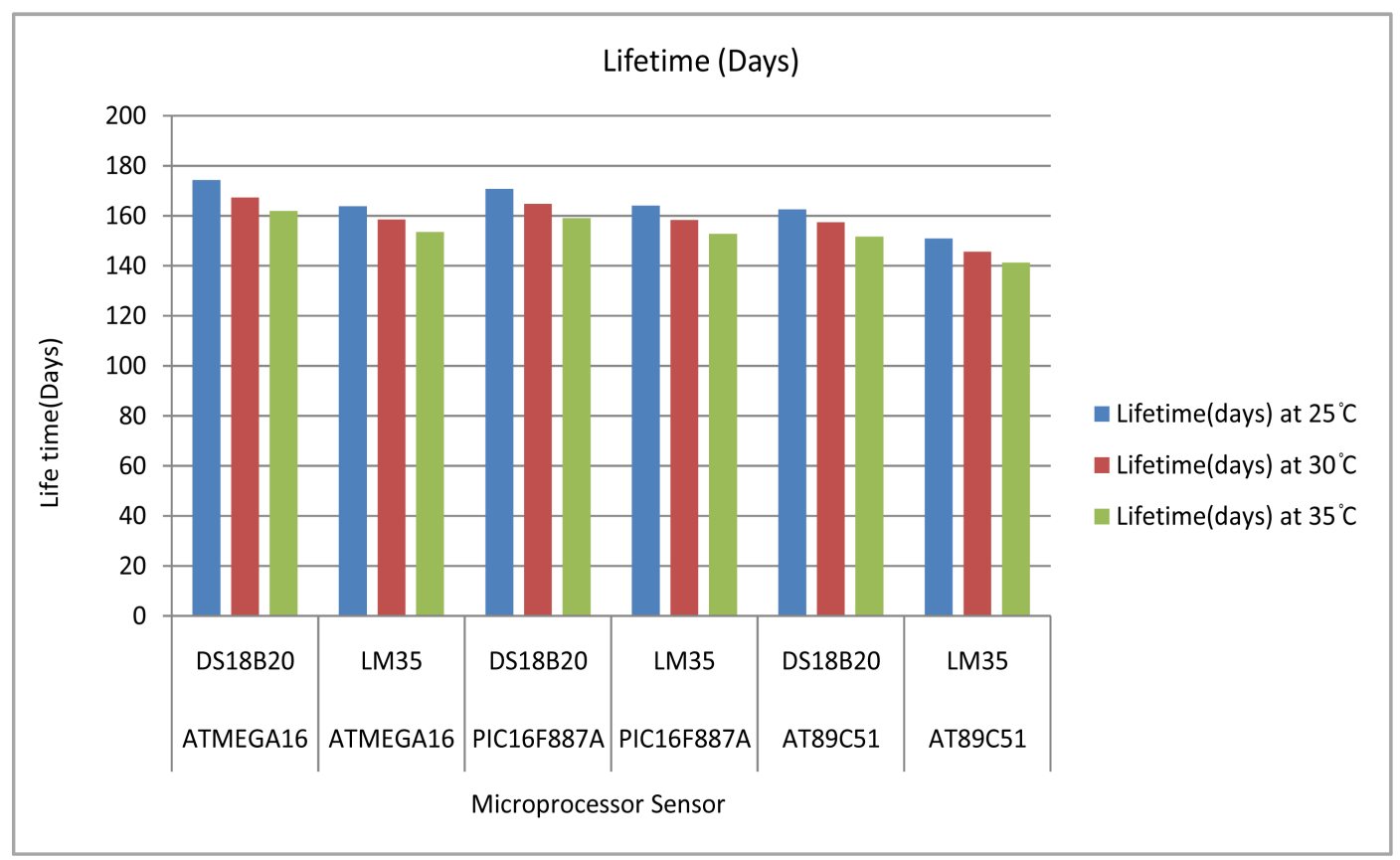

Figure 15. Power consumption comparison of various sensors and microcontrollers.

with DS18B20 digital sensor has the least power consumption, hence the longest lifetime. Further, it is observed that by using differential encoding, power is drastically reduced. By transmitting the difference, the number of bits is reduced. Thus the transmission power is reduced which in turn reduces the overall power consumption. Since this is done in software by the microcontroller, no external hardware is needed. 
Also, by processing the data in parallel form i.e., in BCD format, consumed power is less in comparison to serial processing. Since, the data from the sensor are inherently in $\mathrm{BCD}$ format. This project can further be extended by trying more combinations of microcontrollers and sensors, and also different modulation schemes such as BFSK (binary frequency shift keying) and BPSK (binary phase shift keying).

\section{References}

[1] Gholamzadeh, B. and Nabovati, H. (2008) Concepts for Designing Low Power Wireless Sensor Network. WASET, 35, 559-565.

[2] Chouhan, S., Balakrishnan, M. and Bose, R. (2008) A Framework for Energy Consumption Based Design Space Exploration for Wireless Sensor Nodes. ACM ISLPED, 2008.

[3] Shinghal, K., Noor, A., Srivastava, N. and Singh, R. (2011) Power Measurements of Wireless Sensor Network Node. International Journal of Computational Engineering Science (IJCES), 1, 8-13.

[4] Haase, J., Molina, J. and Dietrich, D. (2011) Power-Aware System Design of Wireless Sensor Networks: Power Estimation and Power Profiling Strategies. IEEE Transactions on Industrial Informatics, 7, 601-613.

[5] Rosiek, S. and Batlles, F.J. (2007) A Microcontroller-Based Data-Acquisition System for Meteoro Logical Station Monitoring. Energy Conversion and Management, 49, 3746-3754. https://doi.org/10.1016/j.enconman.2008.05.029

[6] Shnayder, V., Hempstead, C.B., Werner-Allen, G. and Welsh, M. (2004) Simulating the Power Consumption of Large-Scale Sensor Network Applications. SenSys'04, November 2004.

[7] Akyildiz, I., Su, W., Sankarasubramaniam, Y. and Cayirci, E. (2002) Wireless Sensor Networks: A Survey. Computer Networks, 38, 393-422.

https://doi.org/10.1016/S1389-1286(01)00302-4

[8] Healy, M., Newe, T. and Lewis, E. (2007) Efficiently Securing Data on a Wireless Sensor Network. Journal of Physics. Conference Series, 76, 1-6.

[9] Mini, R.A.F., Machado, M.V., Loureiro, A.A.F. and Nath, B. (2005) Prediction-Based Energy Map for Wireless Sensor Networks. Elsevier Ad-Hoc Networks Journal (Special Issue on Ad Hoc Networking for Pervasive Systems), March 2005.

[10] Rappaport, T.S. (1996) Wireless Communication. Prentice-Hall, Englewood Cliffs. 
Submit or recommend next manuscript to SCIRP and we will provide best service for you:

Accepting pre-submission inquiries through Email, Facebook, LinkedIn, Twitter, etc. A wide selection of journals (inclusive of 9 subjects, more than 200 journals)

Providing 24-hour high-quality service

User-friendly online submission system

Fair and swift peer-review system

Efficient typesetting and proofreading procedure

Display of the result of downloads and visits, as well as the number of cited articles

Maximum dissemination of your research work

Submit your manuscript at: http://papersubmission.scirp.org/

Or contact cs@scirp.org 